\section{Tapering antirheumatic drugs in a resource-poor setting: real-world evidence}

Introduction of biological agents has undoubtedly revolutionised the management of different inflammatory rheumatic conditions; however, for Pakistani patients, it comes with a significant cost burden. We read with interest the article by van Mulligen $e t a l,{ }^{1}$ and we concur with their conclusion that 'financial arguments may influence the decision to taper tumour necrosis factor-inhibitors first'. Being in a resource-poor country, the access to biological therapies is limited in our part of the world, and we would like to share our experience of tapering antirheumatic drugs.

After achieving remission or low disease activity (LDA), dosage reduction of biological disease-modifying antirheumatic drugs (bDMARDs) is an important topic in light of, not only the significant economic burden, but also as increasing number of patients who reach remission or LDA along with carrying the risk of unnecessary adverse events due to overtreatment. Hence, in our practice, we are inclined to keep these patients on the maximum tolerated doses/number of DMARDs and we plan the tapering of bDMARDs soon after achieving remission/LDA. Patients with inflammatory rheumatic disease who are given bDMARDs are followed up with a protocol on 4-6 weekly basis, and validated disease activity assessments are made (Disease Activity Score 28 (DAS 28) for rheumatoid arthritis (RA) ${ }^{2}$; disease activity in psoriatic arthritis and minimal disease activity for psoriatic arthritis $(\mathrm{PsA})^{3}$; and Bath Ankylosing Spondylitis Disease Activity Index, Bath Ankylosing Spondylitis Functional Index, Ankylosing Spondylitis Disease Activity Score ${ }^{4}$ for ankylosing spondylitis (AS)). The protocol involves: continuation of baseline DMARDs and/ or non-steroidal anti-inflammatory drugs (NSAIDs) on the maximum tolerated doses; after 3 months of bDMARDs introduction, if patient achieves remission or LDA, then 30\% reduction in bDMARDs dose or about $30 \%$ prolongation of dosing interval is made; if patient remains in remission or LDA after 4 months of bDMARDs introduction, then $50 \%$ reduction in its dosage or dosing interval is made. In our country, the commonly available and licensed subcutanous bDMARDs include: etanercept, tocilizumab and secukinumab.

In last 1 year, 47 patients were given bDMARDs $(R A=26$, spondyloarthritis $(\mathrm{SpA}) 21(\mathrm{AS}=12, \mathrm{Ps} A=9))$ under our rheumatology services. By June 2020, 45 out of 47 patients have completed at least 3 months of bDMARDs therapy. For this study, only those patients who have completed 3 months of bDMARDs therapy was included $(n=45)$. Among these 45 patients on bDMARDs, 12 patients were using etanercept, 18 patients were on tocilizumab and 15 patients used secukinumab. The median age of these patients was 34 years and a median disease duration of 9 years. Sixty per cent of the cohort was male. It was reassuring to note that $73 \%(n=33)$ of patients have successfully managed to reduce their bDMARDs without any significant flare and without any need for bDMARDs dose escalation (among them, five patients have completely stopped bDMARDs without any flare). All these patients have been maintained on the baseline DMARDs (NSAIDs in the case of AS). Interestingly, patients with $\mathrm{SpA}$ (AS and PsA) were noted to be more successful in reducing their bDMARDs than patients with
RA (18 out of 20 patients, $90 \%$, vs 15 out of 25 patients, $60 \%$; $\mathrm{p}=0.04)$. We also examined whether any particular biological drug has more favourable outcome as regards dose reduction, but no statistical difference was found $(p=0.26)$. Within 1 year of commencing bDMARDs, we managed to reduce the overall exposure of bDMARDs by $41 \%$ in our cohort, reflecting in significantly less cost burden for our patients. Moreover, we plan to use these data to discuss with patients requiring bDMARDs.

We conclude that in our resource-poor clinical setting, a protocol-driven stepwise reduction of bDMARDs was successful as the first choice for tapering towards DMARD-free remission, and these data can potentially be used to help alleviate the anxiety of cost implications associated with bDMARDs.

Muhammad Haroon $\odot$, ${ }^{1}$ Zara Khan, ${ }^{2}$ Maryam Aamer ${ }^{1}$

${ }^{1}$ Department of Rheumatology, Fatima Memorial Hospital \& FMH College of Medicine and Dentistry, Lahore, Pakistan

${ }^{2}$ Department of Medicine, Pakistan Kidney and Liver Institute and Research Center, Lahore, Punjab, Pakistan

Correspondence to Dr Muhammad Haroon, Department of Rheumatology, Fatima Memorial Hospital \& FMH College of Medicine and Dentistry, Lahore, Pakistan; mharoon301@hotmail.com

Contributors All authors conceived the study, its design, coordination, data interpretation and manuscript drafting and editing.

Funding The authors have not declared a specific grant for this research from any funding agency in the public, commercial or not-for-profit sectors.

Competing interests None declared.

Patient and public involvement Patients and/or the public were not involved in the design, or conduct, or reporting, or dissemination plans of this research.

Patient consent for publication Not required.

Provenance and peer review Not commissioned; internally peer reviewed.

(c) Author(s) (or their employer(s)) 2020. No commercial re-use. See rights and permissions. Published by BMJ.

\section{Check for updates}

To cite Haroon M, Khan Z, Aamer M. Ann Rheum Dis Epub ahead of print: [please include Day Month Year]. doi:10.1136/annrheumdis-2020-218703

Received 26 July 2020

Accepted 28 July 2020

\section{SLinked}

- http://dx.doi.org/10.1136/annrheumdis-2020-218731

Ann Rheum Dis 2020;0:1. doi:10.1136/annrheumdis-2020-218703

ORCID iD

Muhammad Haroon http://orcid.org/0000-0002-7383-7990

\section{REFERENCES}

1 van Mulligen E, Weel AE, Hazes JM, et al. Tapering towards DMARD-free remission in established rheumatoid arthritis: 2-year results of the tara trial. Ann Rheum Dis 2020;0:1-8.

2 van der Heijde DM, van 't Hof MA, van Riel PL, et al. Judging disease activity in clinical practice in rheumatoid arthritis: first step in the development of a disease activity score. Ann Rheum Dis 1990:49:916-20.

3 Gossec L, Baraliakos X, Kerschbaumer A, et al. EULAR recommendations for the management of psoriatic arthritis with pharmacological therapies: 2019 update. Ann Rheum Dis 2020;79:700-12.

4 Lukas C, Landewé R, Sieper J, et al. Development of an ASAS-endorsed disease activity score (ASDAS) in patients with ankylosing spondylitis. Ann Rheum Dis 2009;68:18-24. 